\title{
Clinical Significance of Serum Midkine Level as a Biomarker in Diagnosis of Hepatocellular Carcinoma
}

\author{
Maha Z. Omar ${ }^{\mathrm{a}}$, Tamer E. Elazab ${ }^{\mathrm{a}}$, Amira M. Abdelrahman ${ }^{\mathrm{b}}$, Elham F. Mohamed ${ }^{\mathrm{c}}$
}

\begin{abstract}
a Department of Hepatology, Gastroenterology and infectious diseases, Benha Faculty of Medicine, Benha University, Egypt. ${ }^{b}$ Department of Clinical and chemical pathology, Benha Faculty of Medicine, Benha University, Egypt. ${ }^{\mathrm{c}}$ Department of Hepatology, Gastroenterology and infectious diseases, Mansoura University, Egypt.

Correspondence to: Elham F. Mohamed, Department of Hepatology, Gastroenterology and infectious diseases, Mansoura University, Egypt.
\end{abstract}

Email:

drelhamfaruk09@gmail.com

Received: 5 December 2019

Accepted: 26 January 2020

\section{Abstract:}

Background Early diagnosis of hepatocellular carcinoma enhances its effective management. Aim Evaluation of Midkine as a biomarker for diagnosis of hepatocellular carcinoma. Methods: 90 subjects devided into three groups, Group I included $40 \mathrm{HCV}$ patients with liver cirrhosis, Group II included $40 \mathrm{HCV}$ cirrhotic patients with hepatocellular carcinoma and Group III included 10 healthy subjects as a control group. Demographic, laboratory and imaging data were collected. All cirrhotic cases were evaluated by Child-Pugh and MELD scores while BCLC score and Okuda staging were applied for hepatocellular carcinoma cases. Serum Midkine was measured by ELISA technique. Results HCC group had significant elevation in Midkine level compared when to Cirrhotic and Control groups $(3.5 \pm 2.5 \mathrm{ng} / \mathrm{ml}$ versus $1 \pm 0.7 \mathrm{ng} / \mathrm{ml}$ and $0.1 \pm 0.1 \mathrm{ng} / \mathrm{ml})(\mathrm{p}=0.000)$. No significant correlations were found between Midkine and age, sex, site or size of focal lesion, Child classification, MELD score, Okuda staging or BCLC score. ROC analysis showed that the best cut-off value for Midkine was $1.33 \mathrm{ng} / \mathrm{ml}$ and for AFP was $41.3 \mathrm{ng} / \mathrm{ml}$. Area Under the Curve was higher in Midkine than AFP (0.921 and 0.79 respectively) with higher specificity of AFP than Midkine $(97.5 \%$ and $82.5 \%$ respectively) and higher sensitivity of Midkine than AFP (87.5 and $62.5 \%$ respectively). By combination of serum AFP and Midkine, AUC was 0.94 with specificity $97.5 \%$ and sensitivity $87.5 \%$.

Conclusion Midkine may be a sensitive biomarker for diagnosis of hepatocellular carcinoma and combination between alpha-fetoprotein and Midkine increases the accuracy in diagnosis.

Keywords: Hepatocellular Carinoma, Midkine, Cirrhosis, Hepatitis C. 


\author{
Abbreviations: \\ HCV: Hepatitis C Virus. \\ MELD: Model for End-Stage Liver Disease. \\ BCLC: Barcelona Clinic Liver Cancer. \\ ELISA: Enzyme-Linked Immunosorbent Assay. \\ ROC: Receiver Operating Characteristic. \\ AFP: Alpha-FetoProtein. \\ AUC: Area Under the Curve.
}

\section{Introduction}

Hepatocellular carcinoma (HCC) is a major cause of human cancer related death [1]. Cirrhosis, the end stage of chronic liver diseas is a major risk factor for HCC and as it is present in $80-90 \%$ of HCC patients. The HCC risk in patients with liver cirrhosis depends on the degree of fibrosis. HCV and HBV and any agent casusing chronic liver injury and cirrhosis is considered an oncogenic agent e.g aflatoxin (AF), alcoholism and non-alcoholic steatohepatitis (NASH) [2].

In Egypt, HCC is considered an important public health problem. In many Egyptian regional registries, liver cancer is the first most common cancer in men and comes as second in women (3). Regarding the etiology in Egypt, it was found that (95.7\%) of cases were on top of hepatitis viral infections ( $\mathrm{HCV}$ or $\mathrm{HBV}$ ), with predominance for $\mathrm{HCV}$ (91.4\%). This can be explained by the fact that the rate of $\mathrm{HCV}$ in Egypt was the highest in the world, with estimates ranging from 6 to $28 \%$ [4].

Alpha-fetoprotein (AFP) is the most widely tested biomarker in HCC. However, AFP has a suboptimal performance as a serological test for surveillance for 2 reasons; firstly, the fluctuating levels of AFP in patients with cirrhosis might reflect flare of hepatitis viral infection, exacerbation of underlying chronic liver disease or HCC development [5]. Secondly, only a small proportion of tumors at an early stage (10-20\%) are associated with elevated AFP serum levels [6].

Midkine (MK), which is known as neurite growth-promoting factor 2 (NEGF2) is a basic heparin-binding growth factor of low molecular weight. In humans, it is encoded by the MDK gene on chromosome 11 [7]. MK is strongly expressed during embryogenesis whose expression is weakly undetectable in healthy adult tissues [8]. It has role in carcinogenesis of many solid organs including hepatocellular carcinoma through anti-apoptosis, proliferation, mitogenesis, transformation, migration and angiogenesis [9]. Serum MDK is elevated in most HCC cases and may have a potential diagnostic role in AFP-negative and early stage tumors [10]. This study was conducted to evaluate serum Midkine level as a biomarker for diagnosis of hepatocellular carcinoma. 


\section{Subjects and Methods}

\section{Subjects}

This cross-sectional study was conducted on 90 subjects divided into three groups Group I: Included 40 naive $\mathrm{HCV}$ cirrhotic patients without HCC, Group II: Included 40 naive HCV cirrhotic patients with HCC, Group III: Include 10 apparently healthy subjects. The study was conducted at Hepatology, Gastroenterology and Infectious Disease department, Benha University Hospitals during the period from November 2016 to December 2017.

The study was conducted after approval of local ethical committee on research at Benha University and informative written consent was taken from each patient before starting the work. Patients < 18 years old, HCC patients with tumor stage Barcelona D and who had previous treatment or interventional therapy, patients with HBV infection and patients with extra hepatic malignancy were excluded from the study.

\section{Methods}

All participants were subjected to; complete history taking, thorough clinical examination, radiological assessment by abdominal ultrasonography and abdominal tri -phasic CT with contrast (Good enhancement at arterial phase and rapid washout at portal and delayed phases in HCC cases. [11]. Child-Pugh classification [12], Model for End-Stage Liver
Disease (MELD) [13] score were calculated for all cirrhotic and HCC patients. Barcelona Clinic Liver Cancer (BCLC) score [14] and OKUDA staging system [15] also were applied for all HCC patients. Laboratory investigations were performed to all enrolled subjects including; complete blood picture, liver function tests, serum creatinine, Viral markers (HCV Ab and $\mathrm{HBs} \mathrm{Ag}$ ) and Serum Alpha-Fetoprotein (AFP) and Serum Midkine level.

\section{Sampling}

Seven milliliters of venous blood from anterior cubital vein were withdrawn under aseptic conditions, then divided into the following: $1 \mathrm{ml}$ was evacuated in EDTA containing vacutainer for measuring the complete blood count via automated hematology system (Sysmex XE 5000; Sysmex America, Inc), 1.6ml was evacuated in sodium citrate containing vacutainer for PT, INR measurement. The remaining whole blood was evacuated in plain tube without anticoagulant, allowed to clot for 30 minutes at room temperature then centrifuged for 15 minutes at $1000 \times \mathrm{g}$ for serum separation. The separated serum was aliquoted, and stored at $\leq-20^{\circ} \mathrm{C}$ until assayed. It was used for the following assays: Biochemical tests using; Biosystem A15 autoanalyzer (Biosystems SA) by appropriate chemical principles. These tests included the following: Liver 
function tests: serum albumin, total and direct bilirubin, liver enzymes including aspartate aminotransferase (AST) and alanine aminotransferase (ALT), Serum creatinine, Serum AFP level measurement by ELISA assay using Calbiotech AFP ELISA kit E0203-2 with research assay range (10 400ng/ml), Serum Midkine level was measured by Sandwich - ELISA technique using human Midkine ELISA Kit, Elabscience, China E-EL-H2297, with assay range $(0.16-10 \mathrm{ng} / \mathrm{mL})$.

\section{Statistical analysis}

Statistical presentation and analysis was performed using the Statistical Package for Social Sciences (SPSS) vs. 23 (IBM, Endicott, Broome_County, NY, USA). For quantitative data, the mean and standard deviation (SD) were calculated, while frequency and percentage were calculated for qualitative data.The paired samples $\mathrm{T}$ test used to compare the means of two variables for a single group while One way ANOVA (analysis of variance):- Used to compare between more than two groups of numerical (parametric) data followed by post-hoc tukey . Chi-square test was used to compare between groups as regard qualitative data. Correlations were done using Spearman correlation; " $r$ " is the correlation coefficient. The receiver operator characteristic (ROC) curve with $95 \%$ confidence interval (CI) was performed to determine cutoff values for serum midkine and AFP. Sensitivity, specificity, positive predictive value (PPV) and negative predictive value (NPV) in diagnosis of HCC. The threshold of significance was fixed at 5\% level ( $p$ value). Significance was detected according to P-value as follow: $\mathrm{P}>0.05=$ Nonsignificant, $\mathrm{P}<0.05=$ significant and $\mathrm{p}<0.001=$ highly significant.

\section{Results}

This study was conducted on 90 patients who were divided in to $40 \mathrm{HCV}$ cirrhotic patients without $\mathrm{HCC}$ with mean age $59.4 \pm 7$.8years (male $82.5 \%$ and female $17.5 \%$ ), $40 \mathrm{HCV}$ cirrhotic patients with $\mathrm{HCC}$ with mean age $53.9 \pm 6.8$ years (male $62.5 \%$ and female $37.5 \%)$ and ten apparently healthy subjects served as a control group with mean age 35.4 \pm 8.1 years (male $60 \%$ and female $40 \%$ ). There was a highly statistically significant difference between the studied groups as regard age $(\mathrm{p}=0.000)$ which was highest in cirrhotic group and there was male predominance in all groups but it was highest in Cirrhotic group with statistically significant difference $(\mathrm{p}=0.045)$. Child-pugh score was calculated for Cirrhotic and HCC patients and Child A was more predominant in HCC group (25 patients $62.5 \%$ ) while, Child B was more predominant in cirrhotic group (30 patients $75 \%)$. BCLC scoring system was applied for HCC cases and most of HCC cases were in stage A (22) patients (55\%) followed by stage 
C (15) patients (37.5\%) while only

patients were in stage B (7.5\%), Table(1).

Table (1): Demographic data and prognostic indices of HCC patients.

\begin{tabular}{lll}
\hline \multicolumn{1}{c}{ Variables } & & $\begin{array}{l}\text { (Group II) } \\
\text { HCC } \\
\text { No }=\mathbf{4 0}\end{array}$ \\
\hline Age (years) (Mean \pm SD) & & $53.9 \pm 6.8$ \\
Sex $($ No, \%) & Male & $25(62.5 \%)$ \\
& Female & $15(37.5 \%)$ \\
Child grade & & $\%$ \\
(No, \%) & A & $25(62.5)$ \\
& B & $15(37.5)$ \\
& C & $0(0)$ \\
MELD score $($ Mean \pm SD) & & $11.6 \pm 5.4$ \\
& 0 & $0(0)$ \\
BCLC staging & A & $22(55)$ \\
(No, \%) & B & $3(7.5)$ \\
& C & $15(37.5)$ \\
\hline SD = Standard Deviation & &
\end{tabular}

As regard mean level of serum AFP, it was higher among HCC group than cirrhosis group $\quad(134.3 \pm 127.8 \mathrm{ng} / \mathrm{ml} \quad$ versus $6.7 \pm 0.9 \mathrm{ng} / \mathrm{ml}, \mathrm{P}=0.000$ ) and healthy control group $(134.3 \pm 127.8$ versus $1.7 \pm 0.7, \quad \mathrm{P}=$ 0.0001). Figure (1).

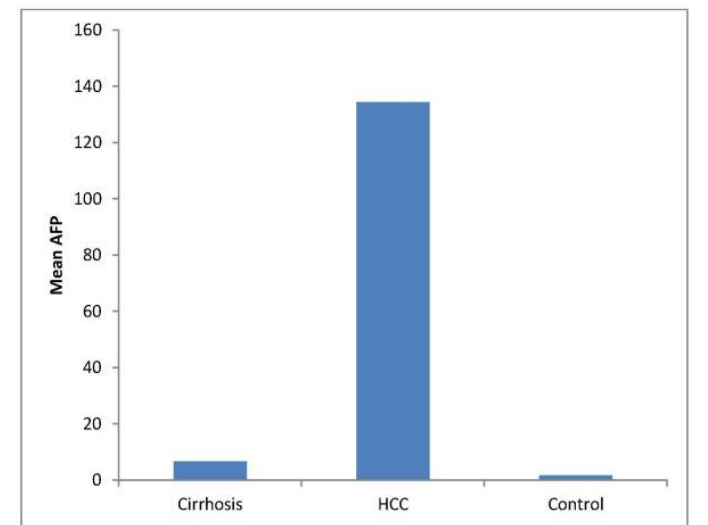

Figure (1): Comparison between the studied groups regarding serum AFP level.

The mean level of serum midkine was much higher in HCC group in comparison to cirrhosis and control groups $(3.5 \pm 2.5 \mathrm{ng} / \mathrm{ml}$ versus $1 \pm 0.7$ and $0.1 \pm 0.1 \mathrm{ng} / \mathrm{ml}$ respectively), $(\mathrm{p}=0.000)$. Meanwhile, serum midkine was more elevated in cirrhosis group when compared with Control group ( $1 \pm 0.7$ versus $0.1 \pm 0.1$ ) but not reaching a statistically significant difference $(\mathrm{P}=0.313)$. Figure (2).



Figure (2): Comparison between the studied groups regarding mean level of serum Midkine

There was no significant corealtion between serum midkine level and serum AFP, different stages of Child score, MELD score, Okuda staging, different stages of BCLC and focal lesion size or site (all $\mathrm{P}$ was $>0.05$ ).

ROC curve was performed to identify the diagnostic performance of both Midkine (MK) and AFP for diagnosis of hepatocellular carcinoma (HCC). As regard serum Midkine, at cutoff of $>1.33 \mathrm{ng} / \mathrm{mL}$ showed a diagnostic specificity of $82.5 \%$, PPV $83.3 \%$, sensitivity of $87.5 \%$ and NPV $86.8 \%$. The area under the curve (AUC) $(95 \% \mathrm{CI})$ was 0.921 (0.87-0.97) and Accuracy was $85 \%$.

As regard serum AFP, at the cutoff $>41.3$ $\mathrm{ng} / \mathrm{mL}$, showed the diagnostic specificity 97.5 $\%$, PPV $96.15 \%$ both higher than Midkine, 
sensitivity of $62.5 \%$, NPV $72.22 \%$, AUC (CI 95\%) was 0.79 (0.69-0.9), both lower than Midkine with highly significant difference $(\mathrm{P}<0.001)$. In combination of serum AFP and Midkine it was shown the diagnostic specificity was $97.5 \%$, PPV 97.2\%, NPV 88.6\% AUC was increased to 0.94 and accuracy was increased to $92.5 \%$. Table (2), figures $(3,4,5)$.

Table (2): Diagnostic Performance of AFP, Midkine and combined AFP and Midkine in diagnosis of HCC.

\begin{tabular}{lcccc}
\hline \multicolumn{1}{c}{ Variables } & $\begin{array}{c}\text { AFP } \\
(\mathbf{n g} / \mathbf{m l})\end{array}$ & $\begin{array}{c}\text { Midkine } \\
(\mathbf{n g} / \mathbf{m l})\end{array}$ & $\begin{array}{c}\text { Combined Comparis } \\
\text { AFP and } \\
\text { Midkine }\end{array}$ & $\begin{array}{c}\text { on } \\
\text { between } \\
\text { AFP and } \\
\text { Midkine }\end{array}$ \\
\hline Area under the & 0.79 & 0.921 & $0.94(0.88-$ & \\
ROC curve & $(0.69-$ & $(0.87-$ & $0.99)$ & \\
(AUC) - CI & $0.9)$ & $0.97)$ & & \\
95 \% & & & & \\
Cut off point & $>41.3$ & $>1.33$ & AFP: $>41.3$ & \\
& $n g / m l$ & $n g / m l$ & ng /ml & \\
& & & Midkine: & $>1.33$ \\
& & & ng/ml & \\
Sensitivity \% & 62.50 & 87.50 & 87.50 \\
Specificity \% & 97.5 & 82.50 & 97.5 \\
PPV \% & 96.15 & 83.3 & 97.2 & \\
NPV \% & 72.22 & 86.8 & 88.6 & \\
Accuracy \% & 80 & 85.0 & 92.5 & \\
P-value & $<\mathbf{0 . 0 0 1 *}$ & $<\mathbf{0 . 0 0 1 *}$ & $<\mathbf{0 . 0 0 1 *}$ & $\mathbf{0 . 0 2 *}$ \\
\hline
\end{tabular}

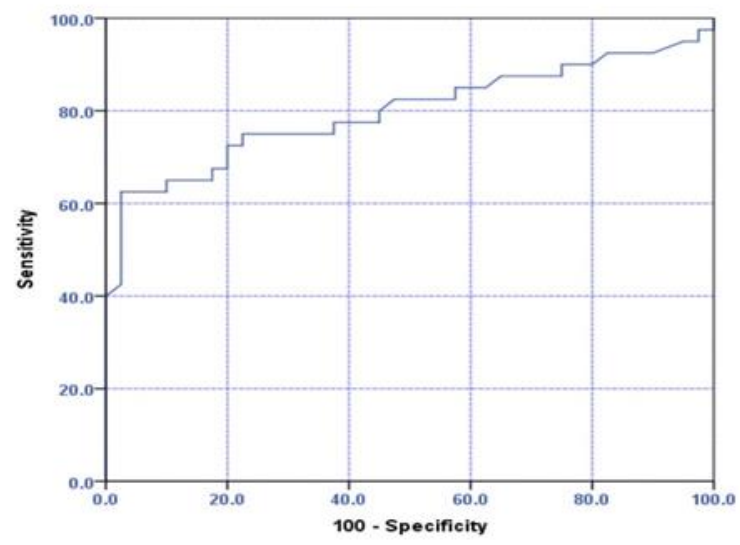

Figure (3): ROC curve for AFP for diagnosis of HCC.

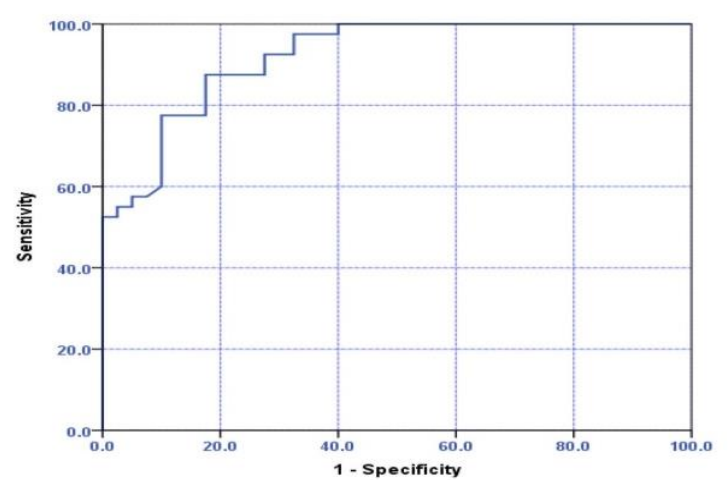

Figure (4): ROC curve for Midkine for diagnosis of HCC.

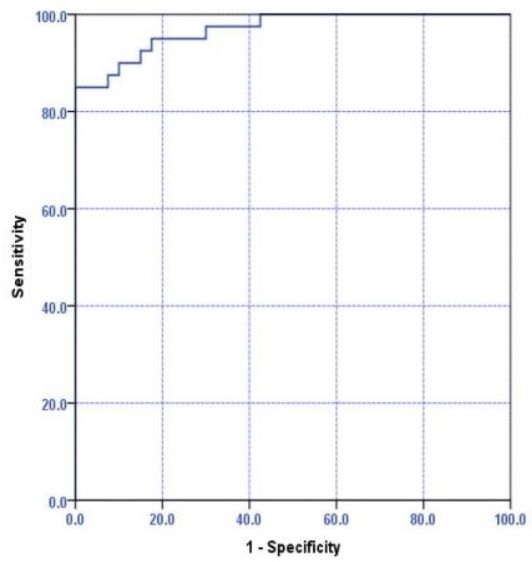

Figure (5): ROC curve for combined AFP and Midkine for diagnosis of HCC.

\section{Discussion}

This study was carried out to estimate the level of serum Midkine in cirrhotic patients with and without HCC and evaluate its potential diagnostic role of HCC.

In the present study the mean age in HCC group was $(53.9 \pm 6.8$ years $)$. This result was in agreement with another study conducted on 2013 which reported that the most frequent age category affected by HCC was between 51 and 60 years [16]. Also, another two 
studies done on 2013 found that the oldest age was in the HCC group (56.05 \pm 5.352 , $55.6 \pm 7.9$ years) respectively $[\mathbf{1 7 , 1 8}]$. In this study, there was male predominance in $\mathrm{HCC}$ group $(62.5 \%)$ and this result was in agreement with two studies on 2013 and another one on 2005 which reported that HCC is more prevalent in male than female $[17,18,19]$ and that can be explained by higher exposure of the males than females to risk factors as HCV virus infection, smoking and alcohol intake, Parkin and colleagues[20].

The present study showed that serum AFP was higher in HCC group with mean level (134.3 $\pm 127.8 \mathrm{ng} / \mathrm{ml})$ followed by Cirrhotic and lowest in Control groups $(6.7 \pm 0.9 \mathrm{ng} / \mathrm{ml}$ and $1.7 \pm 0.7 \mathrm{ng} / \mathrm{ml}$ respectively)with a highly statistically significant difference $(\mathrm{P}=0.000)$. Similar results were obtained by three different studies done on 2015, 2012 and 2010 as they reported that serum AFP was higher among HCC group than liver Cirrhosis group and healthy group $[\mathbf{2 1}, \mathbf{2 2}, \mathbf{2 3}]$.

The present study revealed that serum Midkine level was significantly increased in HCC group with mean level $(3.5 \pm 2.5 \mathrm{ng} / \mathrm{ml})$ followed by Cirrhotic and Control groups ( $1 \pm 0.7$ and $0.1 \pm 0.1 \mathrm{ng} / \mathrm{ml}$ respectively) with a highly statistically significant difference $(\mathrm{P}=$ 0.000) toward HCC group. This result was in agreement with Zhu and colleagues on 2013 and another two studies on 2015 and 2011 who reported that serum Midkine was significantly elevated in patients with hepatocellular carcinoma compared with liver cirrhosis patients and healthy controls $[\mathbf{1 0}, \mathbf{2 1}$, 24].

In the present study there was non-significant correlation between MK and AFP levels and this was in agreement with Zhu and colleagues and Shaheen and colleagues [10, 21] who reported that there was no correlation between both markers but it comes in contrary with Haque and colleagues who found a significant positive correlation between the mean levels of MK and AFP in HCC $(\mathrm{p}<0.05)$ [25]. This difference can be explained by difference in patients number as his study was conducted on 60 patients only.

In the current work, there was no significant correlation between Midkine (MK) serum level and age, sex, radiological characters of the focal lesion or different laboratory parameters all and this result was in partial agreement with Elgarem and coworkers, and Saad and colleagues as they found no significant correlation between MK and age, different laboratory markers except for a significant negative correlation between MK and serum bilirubin level [17, 18]. Also, Shaheen and colleagues on 2015 found a non- significant correlation between $\mathrm{MK}$ and size of the focal lesion [21]. There was non- 
significant correlation between $\mathrm{MK}$ and Barcelona (BCLC) stages in HCC groups. Similar results were reported on 2013 and 2015 as there was a non-significant association between serum MK levels and Barcelona stages [10, 21].

In the present study, MK at a cutoff value > $1.33 \mathrm{ng} / \mathrm{ml}$ had $87.5 \%$ sensitivity, $82.5 \%$ specificity, $83.3 \%$ PPV and $86.8 \%$ NPV with AUC 0.921. This results were higher than AFP at cutoff value $>41.3 \mathrm{ng} / \mathrm{ml}$ which had lower sensitivity (62.5\%), higher specificity (97.5\%) and higher PPV 96.15\% but lower NPV (72.22\%) with AUC (0.79). These results were in agreement with another study done on 2015 which reported that MK had $92.5 \%$ sensitivity, $83.3 \%$ specificity with AUC 0.9 in $\mathrm{HCC}$ diagnosis compared to AFP which had $40 \%$ sensitivity, $96.7 \%$ specificity with AUC 0.6 [21]. Similar results were reported by Zhu and coworkers who found that MK was more sensitive $(86.9 \%)$ with AUC 0.9 than AFP in diagnosis of HCC [10].

The present study revealed that the combination $\mathrm{MK}$ at a cutoff point (>1.33 $\mathrm{ng} / \mathrm{mL})$ and AFP at a cutoff point (>41.3 $\mathrm{ng} / \mathrm{mL}$ ) for discrimination of HCC patients from cirrhotic patients was attaining the same diagnostic sensitivity of MK which was $(87.5 \%)$ but increased the specificity MK from $(82.5 \%)$ to $(97.5 \%)$, and increased the diagnostic sensitivity of AFP from $(62.5 \%)$ to
$(87.5 \%)$ and was attaining the same specificity which was $(97.5 \%)$. This result was supported by Zhu and colleagues who revealed that the diagnostic sensitivity of serum AFP alone was 40\% [10]. However, the combined use of MK and AFP increases the diagnostic sensitivity especially in very early HCC to reach $97 \%$.

But, this results was in disagreement with Elgarem and colleagues who reported that measurement of MK and AFP gene expression did not improve either the specificity or sensitivity in diagnosis and discrimination of HCC from liver cirrhosis [17]. This can be explained that in Elgarem's study serum AFP and tissue expression of Midkine were assessed while in the present study both serum AFP and Midkine were assessed.

The present study revealed that combind use of $\mathrm{MK}$ at cutoff point $(>1.33 \mathrm{ng} / \mathrm{ml})$ and AFP at a cutoff point $(>41.3 \mathrm{ng} / \mathrm{ml})$, the Area under the curve (AUC) was (0.94) which larger than AUC of either MK (0.921) or AFP alone (0.79) and this difference reached a highly significant level $(\mathrm{P}<0.001)$.

This result comes in agreement with another results were reported on 2015 where AUC of combined MK and AFP to diagnose HCC was was larger than that of MK alone (0.963 versus 0.941) or AFP alone (0.963 versus 
0.671) but that difference did not reach a significant level [21].

\section{Conclusion}

Midkine (MK) may serve as a novel diagnostic tumor marker for the detection of hepatocellular carcinoma as its level was found to be significantly elevated in $\mathrm{HCC}$ patients. Combining serum midkine to alpha fetoprotein led to an increase in the sensitivity and specificity of hepatocellular carcinoma detection than its use alone. Further studies with larger population are needed to justify its implementation in clinical practice.

\section{References}

1. Fitzmorris $\mathrm{P}$ and Singal AK. Surveillance and diagnosis of hepatocellular carcinoma. Gastroenterol Hepatol. 2015;11:38-46.

2. Sene WR, Zhang $\mathrm{Y}$ and Chen Y. Hepatocellular Carcinoma: Focus on Different Aspects of Management. ISRN Oncol. 2012;1-12.

3. Baghdady I, Fouad F, Sayed M, Shoaib A, Salah Y, Elshayeb E, et al. Serum markers for the early detection of hepatocellular carcinoma in patients with chronic viral hepatitis C infection. Menoufia Med J 2014; 27:744-750.

4. Mohamoud YA, Mumtaz GR, Riome S, Miller D and Abu-Raddad LJ. The epidemiology of hepatitis $\mathrm{C}$ virus in Egypt: a systematic review and data synthesis. BMC Infectious Disease 2013; 13:288.

5. Di Bisceglie AM., Sterling RK., Chung RT, Everhart JE, Dienstag JL, Bonkovsky HL, Wright EC, et al. Serum alpha-fetoprotein levels in patients with advanced hepatitis $\mathrm{C}$ : results from the
HALT-C Trial. Journal of Hepatology 2005; 43:434-441.

6. Villanueva A., Minguez B., Forner A., Reig M., and Llovet JM. Hepatocellular carcinoma: novel molecular approaches for diagnosis, prognosis, and therapy. Annual Review of Medicine 2010; 61:317328.

7. Ibusuki M, Fujimori H, Yamamoto Y, Ota K, Ueda M, Shinriki S, et al. Midkine in plasma as a novel breast cancer marker. Cancer Science 2009: 100:1735-1739.

8. Muramatsu $\mathrm{T}$ and Kadomatsu K. Midkine: an emerging target of drug development for treatment of multiple diseases. $\mathrm{Br} J$ Pharmacol. 2014; 171:811-903.

9. Muramatsu T. Midkine and pleiotrophin: two related proteins involved in development, survival, inflammation and tumorigenesis. J. Biochem. (Tokyo) 2002; 132:359-371.

10.Zhu WW, Guo JJ, Guo L, Jia HL, Zhu M, Zhang JB, et al. Evaluation of midkine as a diagnostic serum biomarker in hepatocellular carcinoma. Clin Cancer Res. 2013; 19:3944-3954.

11. Mirgalia R, Pietrosi G, Maruzzelli L, Petridis I, Caruso S, Mamone G, et al. Predictive factors of tumour response to trans-catheter treatment in cirrhotic patients with hepatocellular carcinoma: a multivariate analysis of pre-treatment findings. World J Gastroentrol 2007; 13:6022-6026.

12.Pugh, RN, Murray-lyon, IM, Dawson, JL, Pietroni MC and Wiliam R. Transection of the esophagus for bleeding of esophageal varices. Br J Surg 1973; 60:646-649.

13. Kamath PS and Kim WR. The model for end-stage liver disease (MELD). Hepatology 2007; 45:797805.

14. Howard JW and Jil OJ. Performance status in patients with cancer. JAMA Oncology 2015; 1:998998 . 
15. Okuda K, Ohtsuki T, Obata H, Tomimatsu M, Okazaki N, Hasegawa H, et al. Natural history of hepatocellular carcinoma and prognosis in relation to treatment. Study of 850 patients.Cancer 1985; 56:918-928.

16. Shaker M, Abdella H, Khalifa M and El Dorry A. Epidemiological characteristics of hepatocellular carcinoma in Egypt: a retrospective study of 1313 cases. Liver Intrnational 2013; 33:1601-1606.

17. El-Garem H, Abdel-Hafez H, Fouad A, Al Akel W, Atia M, Salah M, et al. Tissue Biomarkers in the early detection of hepatocellular carcinoma among Egyptian patients withchronic hepatitis C: A possible

21. Shaheen KY, Abdel-Mageed AI, Safwat E, and AlBreedy AM. The value of serum midkine level in diagnosis of hepatocellular carcinoma. Int J Hepatol. 2015;1-6.

22. Gomaa A, Hendy O, Aboraia G, H Attia and E Nafei. The diagnostic Value of Peripheral blood Glypican-3 in patients with hepatocellular carcinoma. World J Med Sci. 2012; 7:105-112.

23. Liu H, Li P, Zhai Y, Qu CF, Zhang LJ, Tan YF, et al. Diagnostic value of Glypican-3 in serum and liver for primary hepatocellular carcinoma. World $\mathrm{J}$ Gastroenterol. 2010; 16:4410-4415.
Genetic Profile. British Journal of Medicine and Medical Research 2013; 3:1858-1870.

18. Saad Y, El-Serafy M, Eldin MS, Abdellatif Z, Khattab H, Elbaz T, et al. New genetic markers for diagnosis of hepatitis $\mathrm{C}$ related hepatocellular carcinoma in Egyptian patients. $J$ Gastrointestin Liver Dis. 2013; 22:419-425.

19.El-Zayadi AR, Badran HM, Barakat EM, Attia MEL D, Shawky S, Mohamed MK, et al. Hepatocellular carcinoma in Egypt: a single center study over a decade. World J Gastroenterol. 2005; 11:5193-5198.

20. Parkin DM, Ferlay J and Pisani P. Global cancer statistics, 2002. CA Cancer J Clin. 2005; 55:74-108.

24.Hung YJ, Zoe HYL, Cheng TI, Liang CT, Kuo TM and Kao KJ. Serum Midkine as a Prognostic Biomarker for Patients with Hepato-cellular Carcinoma. American Journal of Clinical Pathology. 2011; 4:594-603.

25. Haque S, Tanweeruddin M, Kumari B, Kumar A, Kumar S, Kumar A, et al. Status of serum alpha-feto protein (AFP) and Midkine (MK) levels in patients with hepatocellular carcinoma. Journal of Basic Research in Medical Science. 2015; 2:15-19.

To cite this article: Maha Z. Omar, Tamer E. Elazab, Amira M. Abdelrahman, Elham F. Mohamed. Clinical Significance of Serum Midkine Level as a Biomarker in Diagnosis of Hepatocellular Carcinoma. BMFJ 2020; 37 (Internal medicine and Hepatology):37-46. DOI: $10.21608 / \mathrm{bmfj} .2020 .20583 .1185$ 